\title{
Novel complement factor $H$ mutation, a case report of atypical hemolytic uremic syndrome
}

\author{
Rodrigo Andrés Sepúlveda, Rodrigo Tagle, Aquiles Jara \\ Departamento de Nefrología, Facultad de Medicina, Pontificia Universidad Católica de Chile, Chile
}

Received: December 19, 2016

Accepted: February 5, 2017

Online Published: February 22, 2017

DOI: $10.5430 /$ crim.v4n2p13

URL: https://doi.org/10.5430/crim.v4n2p13

\begin{abstract}
Atypical hemolytic uremic syndrome (aHUS) is a rare but catastrophic disease. It is characterized by a triad of microangiopathic hemolytic anemia, thrombocytopenia and acute renal failure. When the aHUS is primary, the cause is due to mutations in proteins that regulate the alternative pathway of complement, such as Factor H, Factor I, Factor B, C3, Membrane Co-Factor Protein and Thrombomodulin. Usually primary aHUS is associated with other amplifiers complement factors. We present a case of aHUS in a 25-year-old female patient; she presented with malignant hypertension and severe renal failure. After a widespread study, the etiology of the aHUS was a mutation in the complement factor $\mathrm{H}$, not previously described in the literature (p.Tyr1177His). After treatment with Eculizumab (C5 inhibitor monoclonal antibody), she recovered renal function with not hemodialysis requirements.
\end{abstract}

Key Words: Atypical hemolytic uremic syndrome, Complement factor $\mathrm{H}$

\section{INTRODUCTION}

Hemolytic uremic syndrome (HUS) is characterized by a triad of thrombocytopenia, microangiopathic hemolytic anemia and acute renal failure. The main cause of HUS is the infection by shiga toxin-producing Escherichia coli (STEC). The principal serotypes associated with HUS are O157:H7, O111:H8, O103:H2 and O104:H4. ${ }^{[1,2]}$ This infection is responsible for $90 \%$ of cases of HUS (HUS-STEC). ${ }^{[2-4]}$ It mainly affects children and has a good prognosis. ${ }^{[5]}$ The remaining $10 \%$ of cases has poor prognosis, are not associated with STEC and this clinical picture was called Atypical Hemolytic Uremic Syndrome (aHUS). ${ }^{[6]}$

The aHUS is a rare disease with annual incidence of 0.5 to 2 cases per million populations. ${ }^{[5]}$ It seems to have a higher incidence in adults. ${ }^{[6]}$ Its consequences can be catastrophic; with $10 \%-25 \%$ mortality rate in the acute phase (higher in child population). ${ }^{[1,4]}$ Its main problem is the development of end stage renal disease (ESRD), $50 \%$ of patients will be dialysis-dependent in acute phase $\mathrm{e}^{[1,4,5]}$ and this percentage increasing over time.

The pathogenesis of aHUS corresponds to a thrombotic microangiopathy (TMA). TMA is characterized by microangiopathic hemolytic anemia, thrombocytopenia and organ failure; ${ }^{[7]}$ in HUS, the organic affectation is limited or predominant in the kidney.

Initially, all cases of HUS not associated with STEC were classificated like aHUS. However, the etiology of microangiopathy in these cases can to be drugs, infections, cancer, autoimmune disorders, organ transplantation, ischemia, but the majority were idiopathic. Later, idiopathic cases were associated to alternative complement pathway mutations. The primary aHUS is characterized by excessive activation of the

*Correspondence: Rodrigo Andrés Sepúlveda; Email: rrsepulveda@uc.cl; Address: Diagonal Paraguay 362, Santiago, Chile. 
complement alternative pathway, causing endothelial damage with release of von Willebrand factor, tissue factor and exposure of subendothelial collagen; this produces activation of primary and secondary hemostasis. Currently, primary aHUS is defined by the presence of genetic alternative complement pathway mutation. Conversely, secondary TMA is associated with an external factor that triggers the microangiopathy. Secondary causes of TMA can be the cause themselves and/or acts as complement amplifiers factors on a genetic vulnerability. ${ }^{[7,8]}$

\section{Case presentation}

A 25-year-old female, with history of eating behavior disorder, obesity and hypertension (diagnosed at age 22). After bariatric surgery (24-year-old), hypertension was cured. She smokes 4 pack-years index, occasionally consume alcohol and not use of illicit drugs. The only medication was oral contraceptives. No history of allergies and no history of family kidney disease.

At the age of 25-year-old, her blood pressures started to increase and restart antihypertensive therapy. Secondary hypertension etiologies were studied: serum creatinine
$0.8 \mathrm{mg} / \mathrm{dl}$, normal urinalysis, urinary metanephrines and thyroid tests were normal. CT-angiography ruled out kidney anatomic defect and renal artery stenosis. However, plasma renin activity was $22.8 \mathrm{ng} / \mathrm{ml} / \mathrm{h}$ (normal: 1.3 to $4 \mathrm{ng} / \mathrm{ml} / \mathrm{h}$ ) and plasma aldosterone concentration was $60 \mathrm{ng} / \mathrm{dl}$ (normal: 1.8 to $23.2 \mathrm{ng} / \mathrm{dl})$.

Later, she consulted in emergency room because of abdominal pain of 3 days evolution and headache. She never had diarrhea, nausea, vomiting or fever.

She was found to have acute kidney injury (serum creatinine $2.99 \mathrm{mg} / \mathrm{dl}$ ), thrombocytopenia (platelets $83,000 / \mathrm{mm}^{3}$ ), and microangiopathic hemolytic anemia evidenced by hemoglobin $9.7 \mathrm{~g} / \mathrm{dl}$ and schistocytes on peripheral blood smear. Treatment for presumed Thrombotic Thrombocytopenic Purpura (TTP) was initiated at an outside institution with high-dose intravenous steroids and plasmapheresis. During this treatment, her renal function continued decline.

Hemodialysis was initiated. Her ADAMTS13 activity was found normal (85\%). Quantitative assessments of complement levels were normal, including $\mathrm{C} 3$ and $\mathrm{C} 4$ at 78 and $14.6 \mathrm{mg} / \mathrm{dl}$, respectively. However complement levels were measured after plasmapheresis.

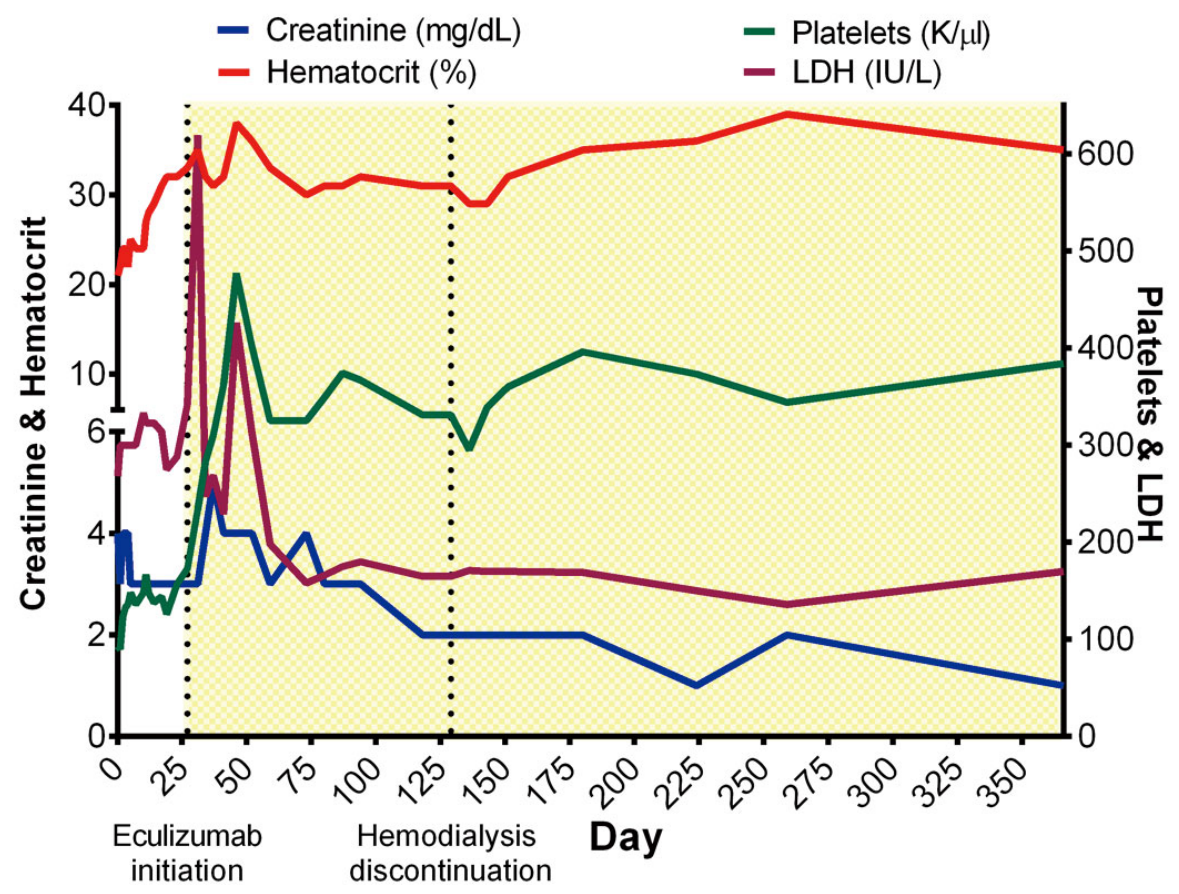

Figure 1. Evolution parameters associated with microangiopathy. LDH: lactate dehydrogenase; Yellow Zone: Eculizumab administration

Previous to her transfer a percutaneous kidney biopsy was done, revealing "Thrombotic angiopathy with arteriolar and capillary thrombosis plus acute tubular necrosis. No immune deposits were detected". With this background, the diagnosis of aHUS was suspected and the patient was transferred to our institution. 
After transfer, etiologic study of aHUS was completed: fecal, blood and urine cultures, viral tests (HIV, HBV, HCV and viral respiratory panel) were negative. Immunological tests (antinuclear antibodies, anti-DNA antibodies, anti-neutrophil cytoplasmic antibody, anti-streptolysin-O, antiphospholipid antibodies) were negative. It was not possible to measure anti-factor $\mathrm{H}$ antibodies due to plasmapheresis. Pregnancy and other diseases that could cause secondary TMA were ruled out.

A diagnosis of primary aHUS was made, plasmapheresis was discontinued and eculizumab therapy was initiated. Prior to Eculizumab administration she was immunized against $\mathrm{N}$. Meningitidis.

Genetic study was performed in Centogene AG laboratory (Rostock, Germany). The DNA sequencing include: Complement factor $\mathrm{H}(\mathrm{CFH})$, Factor I (CFI), Factor B (CFB), C3, Factor H-Related protein (CFHR), Membrane Cofactor Protein (MCP), Thrombomodulin (THBD). Furthermore, deletion or duplication of CFHR was studied by MLPA (multiplex ligation-dependent probe amplification). This study showed a heterozygous variant of uncertain significance for $\mathrm{CFH}$, with a change of thymine by cytosine in the nucleic acid 3529; which determines an amino acid change at position 1,177 of the primary polypeptide: tyrosine by histidine (p.Tyr1177His).

The patient was discharged with chronic hemodialysis treatment three times per week and Eculizumab therapy. She showed early hematological remission and slow renal function improvement (see Figure 1). Three months after Eculizumab treatment, hemodialysis was discontinued and the creatinine clearance improved to $30 \mathrm{ml} / \mathrm{min}$.

The patient has remained clinically stable for 12 months to date with maintenance Eculizumab dosing of 1,200 mg IV every 2 weeks. Currently her serum creatinine is $1.48 \mathrm{mg} / \mathrm{dl}$ (MDRD-4: $42 \mathrm{ml} / \mathrm{min} / 1.73 \mathrm{~m}^{2}$ ).

\section{Discussion}

The patient has a TMA with predilection by kidneys and negative study for TTP and HUS-STEC. This is in line with aHUS. Other causes that may produce a predominant kidney affectation by TMA are infection by S. pneumoniae and Influenza virus producer of neuraminidase, HIV and other viral infection, chemotherapy, pregnancy, postpartum, cancer and autoimmune disorders. ${ }^{[8]}$ All these etiologies were discarded, so secondary TMA was unlikely.

Then, the suspected diagnosis was a primary aHUS associated with triggering factors. The condition of "primary" implies an alternative complement pathway defect. It has

Published by Sciedu Press been described that $40 \%-70 \%$ of aHUS present a genetic mutation ${ }^{[4,8,9]}$ and approximate $50 \%$ have a triggering factor. ${ }^{[8]}$ Primary aHUS series describe that aHUS is more common in young adult. ${ }^{[10]}$

In our patient, factors that may have triggered the disease were oral contraceptive therapy, ${ }^{[4]}$ gastrointestinal viral infectious process ${ }^{[8]}$ and development of malignant hypertension. ${ }^{[7]}$

Of all cases with alternative complement pathway defect (primary aHUS); $47 \%$ have a mutation in $\mathrm{CFH}, 14 \%$ in MCP, $10 \%$ in THBD, $8 \%$ in CFI and $8 \%$ in C3. Only $6 \%$ have anti-CFH antibodies. ${ }^{[4]}$ Most of these mutations are heterozygous. ${ }^{[4]}$

In the complement activation, the classical and lectin pathway needs an external factor to its activation. However, alternative pathway tends to spontaneous intravascular activation by the generation of $\mathrm{C} 3 \mathrm{~b}$. Then, $\mathrm{C} 3 \mathrm{~b}$ binds to the cell surface, activates $\mathrm{C} 5$, and then, promotes membrane attack complex formation. ${ }^{[11]}$ The presence of fluid phase and cell surface inhibitors prevent a massive activation of complement in the normal state. CFH is the most important alternative complement pathway inhibitor. The cells capture $\mathrm{CFH}$ on their surface, to protect of $\mathrm{C} 3 \mathrm{~b}$ binding and complement mediated injury. In fact, the function of $\mathrm{C}$ reactive protein is to enhance $\mathrm{CFH}$ recruitment on cell surface. ${ }^{[11]}$ Malignant cells and various microorganisms bind $\mathrm{CFH}$ as a mechanism to avoid complement mediated destruction. ${ }^{[11]}$

Our patient has a variation in CFH at position 1,177 of the primary polypeptide. This variation is not described in the literature and generates a change of amino acid tyrosine by histidine.

If this variant of uncertain significance is a non-conservative or conservative mutation is unknown. To answer this question is necessary to evaluate if this protein variant can change conformation structure and/or modify active site.

Tyrosine is a hydrophilic amino acid of aromatic neutral nature; however histidine is a hydrophilic but basic nature. Both amino acids are from different classes; therefore, this amino acidic replacement may modify its structure and then its function. ${ }^{[12]}$ Histidine tends to be charged and exposed to solvent in a higher degree than tyrosine. If this change occurs in the active site of protein, it may affect its function. For example, in cholesteryl ester storage disease exists the same missense mutation. ${ }^{[13]}$ Based on this first argument we may say that the variant of our patient is able to change the $\mathrm{CFH}$ properties.

The CFH gene is located in the long arm of chromosome 
1 , in a region where a group of regulatory genes of complement activation exist. It is characterized by expressing specific domains: short consensus repeat (SCR) or control unit complement proteins (CCP). ${ }^{[11,14,15]}$ Factor H contains 20 of these domains (see Figure 2).

a)
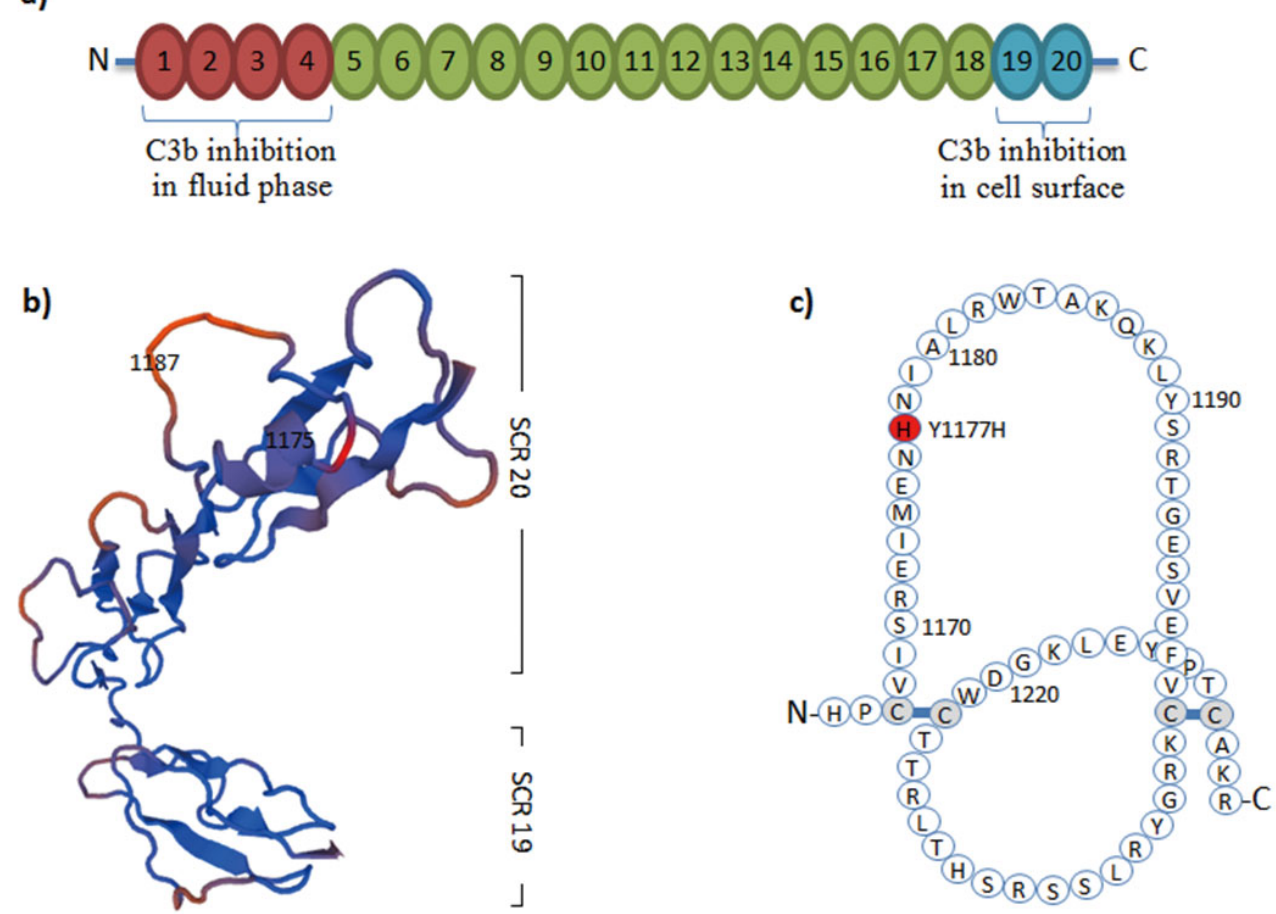

Figure 2. CFH and SCR domains. a) CFH scheme: shows its 20 SCR domains; SCR1-4 are essential to C3b inhibition by binding in fluid phase, and SCR19-20 are essential to C3b inhibition in cell surface. b) SCR19-20 modeling: it shows "in red" the site of our patient mutation. c) SCR20 scheme: shows polyanionic substances binding site (modified from reference 17), our patient mutation is "in red"; CFH: complement factor H. SCR: short consensus repeat

Factor $\mathrm{H}$ defects and function alterations have been associated with diseases such as aHUS, age related macular degeneration and C3 glomerulopathy. ${ }^{[11]}$ The domains SCR1-4 attach to C3b, inhibiting its function. The SCR19-20 region of $\mathrm{CFH}$, localized at carboxyl terminal portion, is essential for its inhibitory action on cell surface and for its protective action in the kidney by binding polyanionic substances. ${ }^{[16]}$ An alteration in carboxyl terminal portion of $\mathrm{CFH}$ is associated with aHUS by a complement mediated endothelial injury. By contrast, alteration in $\mathrm{N}$-terminal portion of $\mathrm{CFH}$ is associated with $\mathrm{C} 3$ glomerulopathy. ${ }^{[5]}$

The amino acid 1177 is located at the binding site of SCR20 factor $\mathrm{H}^{[17]}$ (see Figure 2). More than $50 \%$ of mutations in Factor $\mathrm{H}$ are produced in the SCR20 region. ${ }^{[4,6]}$ Familial cases of aHUS are associated to SCR20 CFH mutation. ${ }^{[4]}$ Interestingly, SCR20 domain has the main role in the inhibitory action of Factor $\mathrm{H}$ in the alternative complement pathway. Consequently, any SCR20 mutation could cause significant risk for primary aHUS. ${ }^{[11]}$
In addition, Besbas et al. reported a variant in the same location (p.Tyr1177Cys) that correspond a mutation associated with primary aHUS in a neonate. ${ }^{[18]}$

Based on all these arguments, it is possible to conclude that the heterozygote polymorphism p.Tyr1177His on Factor $\mathrm{H}$ is a mutation, not reported in the literature, that may cause primary aHUS due to SRC20 domain modification.

In general, Factor $\mathrm{H}$ mutation is responsible for $30 \%$ of cases of aHUS. Most are heterozygous and have a penetrance of $48 \%$. The prognosis of the Factor $\mathrm{H}$ mutation is bad; $30 \%$ of infants and $4 \%$ of adults die in the acute episode. ${ }^{[19]}$ Of the survivors, $30 \%$ of infants and about $50 \%$ of adults are dialysis dependent. After 5 years, $77 \%$ of patients have died or are on dialysis. ${ }^{[19]}$ It has a recurrence of $70 \%-85 \%$ in renal transplantation, being higher if it affects the $\mathrm{C}$-terminal portion (site of patient variation). ${ }^{[20]}$ Patients with Factor $\mathrm{H}$ mutation have a high incidence of cardiovascular disease and increased mortality. ${ }^{[1]} 8 \%$ of cases of aHUS associated with Factor $\mathrm{H}$ mutation are triggered by pregnancy or oral 
contraceptive drugs, like our patient. ${ }^{[1]}$

In conclusion, our patient has a CFH mutation (not previously reported) associated with triggering factors that produced an aHUS. Because $\mathrm{CFH}$ mutation confers poor prognosis, so she will need treatment with Eculizumab for a long time.

\section{ACKNOWLEDgements}

We express our thanks to Pedro Figueroa MD and to Ms. Rosa Godoy for their help in this case.

\section{CONFLicts of InTEREST Disclosure}

The authors have no competing interests to declare.

\section{REFERENCES}

[1] Noris M, Remuzzi G. Atypical Hemolytic-Uremic Syndrome. N Engl J Med. 2009; 361(17): 1676-87. PMid: 19846853 http: //dx.doi.org/10.1056/NEJMra0902814

[2] Noris M, Mescia F, Remuzzi G. STEC-HUS, atypical HUS and TTP are all diseases of complement activation. Nat Rev Nephrol. 2012; 8(11): 622-33. PMid: 22986360 http://dx.doi.org/10.1038 /nrneph.2012.195

[3] Nayer A, Asif A. Atypical Hemolytic-Uremic Syndrome: A Clinical Review. American Journal of Therapeutics. 2016; 23(1): e151-8. PMid: 24681522 http://dx.doi.org/10.1097/MJT.0b013e3 $1829 \mathrm{~b} 59 \mathrm{dc}$

[4] Noris M, Caprioli J, Bresin E, et al. Relative Role of Genetic Complement Abnormalities in Sporadic and Familial aHUS and Their Impact on Clinical Phenotype. Clin J Am Soc Nephrol. 2010; 5(10): 1844-59. PMid: 20595690 http://dx.doi.org/10.2215/CJN.02210310

[5] Noris M, Remuzzi G. Glomerular Diseases Dependent on Complement Activation, Including Atypical Hemolytic Uremic Syndrome, Membranoproliferative Glomerulonephritis, and C3 Glomerulopathy: Core Curriculum 2015. Am J Kidney Dis. 2015; 66(2): 359-75. PMid: 26032627 http://dx.doi.org/10.1053/j.ajkd.2015.03.04

[6] Loirat C, Frémeaux-Bacchi V. Atypical hemolytic uremic syndrome. Orphanet J Rare Dis. 2011; 6: 60. PMid: 21902819 http: //dx.d oi.org/10.1186/1750-1172-6-60

[7] Riedl M, Fakhouri F, Le Quintrec M, et al. Spectrum of complementmediated thrombotic microangiopathies: pathogenetic insights identifying novel treatment approaches. Semin Thromb Hemost. 2014; 40(4): 444-64. PMid: 24911558 http://dx.doi.org/10.1055 /s-0034-1376153

[8] Nester CM, Barbour T, de Cordoba SR, et al. Atypical aHUS: State of the art. Mol Immunol. 2015; 67(1): 31-42. PMid: 25843230 http://dx.doi.org/10.1016/j.molimm.2015.03.246

[9] Bresin E, Rurali E, Caprioli J, et al. Combined complement gene mutations in atypical hemolytic uremic syndrome influence clinical phenotype. J Am Soc Nephrol. 2013; 24(3): 475-86. http: //dx.doi.org/10.1681/ASN. 2012090884

[10] Fremeaux-Bacchi V, Fakhouri F, Garnier A, et al. Genetics and outcome of atypical hemolytic uremic syndrome: a nationwide French series comparing children and adults. Clin J Am Soc Nephrol. 2013; 8(4): 554-62. http://dx.doi.org/10.2215/CJN. 04760512
[11] Ferreira VP, Pangburn MK, Cortés C. Complement control protein factor $\mathrm{H}$ : The good, the bad, and the inadequate. Mol Immunol. 2010; 47(13): 2187-97. PMid: 20580090 http://dx.doi.org/10.1016 /j.molimm.2010.05.007

[12] Bordo D, Argos P. Suggestions for "safe" residue substitutions in site-directed mutagenesis. J Mol Biol. 1991; 217(4): 721-9. PMid: 2005621

[13] Pagani F, Zagato L, Merati G, et al. A histidine to tyrosine replacement in lysosomal acid lipase causes cholesteryl ester storage disease. Hum Mol Genet. 1994; 3(9): 1605-9. PMid: 7833918

[14] Abarrategui-Garrido C, Martínez-Barricarte R, López-Trascasa M, et al. Characterization of complement factor H-related (CFHR) proteins in plasma reveals novel genetic variations of CFHR1 associated with atypical hemolytic uremic syndrome. Blood. 2009; 114(19): 426171. PMid: 19745068 http://dx.doi.org/10.1182/blood-200 9-05-223834

[15] Kimura Y, Inoue N, Fukui A, et al. A short consensus repeatcontaining complement regulatory protein of lamprey that participates in cleavage of lamprey complement 3. J Immunol. 2004; 173(2): 1118-28. PMid: 15240701

[16] Clark SJ, Ridge LA, Herbert AP, et al. Tissue-specific host recognition by complement factor $\mathrm{H}$ is mediated by differential activities of its glycosaminoglycan-binding regions. J Immunol. 2013; 190(5): 2049-57. http://dx.doi.org/10.4049/jimmunol.1201751

[17] Józsi M, Heinen S, Hartmann A, et al. Factor H and atypical hemolytic uremic syndrome: mutations in the C-terminus cause structural changes and defective recognition functions. J Am Soc Nephrol. 2006; 17(1): 170-7. PMid: 16338962 http://dx.doi.o $\mathrm{rg} / 10.1681$ /ASN .2005080868

[18] Besbas N, Gulhan B, Karpman D, et al. Neonatal onset atypical hemolytic uremic syndrome successfully treated with eculizumab. Pediatr Nephrol. 2013; 28(1): 155-8. PMid: 22956028 http: //dx.doi.org/10.1007/s00467-012-2296-4

[19] Kavanagh D, Goodship TH, Richards A. Atypical hemolytic uremic syndrome. Semin Nephrol. 2013; 33(6): 508-30. http://dx.doi .org/10.1016/j. semnephrol.2013.08.003

[20] Zuber J, Le Quintrec M, Morris H, et al. Targeted strategies in the prevention and management of atypical HUS recurrence after kidney transplantation. Transplant Rev (Orlando). 2013; 27(4): 117-25. PMid: 23937869 http://dx.doi.org/10.1016/j.trre. 2013 .07 .003 